\title{
Supporting Postsecondary Faculty Transition to Rapid Online Teaching \& Learning
}

\author{
Michelle E. Bartlett \\ North Carolina State University \\ mebartle@ncsu.edu \\ Carrol L. Warren \\ North Carolina State University \\ clwarren@ncsu.edu \\ Diane D. Chapman \\ North Carolina State University \\ ddchapma@ncsu.edu
}

\begin{abstract}
North Carolina postsecondary faculty, similar to faculty around the world, who prepared their spring 2020 semester courses for face-to-face delivery, were required to quickly transition to Rapid Online Teaching and Learning (ROTL). This transition was expected within a short time frame, often one to two weeks, and for many faculty members, both time and resources to incorporate design practices found in high-quality online courses were limited. Faculty members demonstrated great determination and grit as they shifted to remote teaching and learning with a focus on the student success, even while feeling overwhelmed and disrupted themselves. Researchers examined two faculty-support programs designed to assist with the shift to online teaching during the COVID-19 crisis: one at a research-intensive, land-grant university and another for faculty at 58 community colleges, some of whom are enrolled in a CPED Ed.D. program. Lessons learned and thoughts on planning for future semesters are examined.
\end{abstract}

\section{KEYWORDS}

rapid online teaching \& learning, quick transition, COVID-19, faculty support

\section{INTRODUCTION}

Faculty schedules for the spring 2020 semester were interrupted with the expectation that courses were shifting to an online delivery in a matter of days. Preparation for online course delivery requires time and tools in order to be considered as a highquality online learning environment (Hodges et al., 2020). Faculty members, including those who are also students in CPED graduate programs, spent countless hours shifting content from the seated classroom to a Rapid Online Teaching and Learning (ROTL) virtual space in order to keep students progressing through the semester. This paper provides an overview of projects created by faculty scholars who teach and provide leadership in a CPED program to support both university and community college educators during the rapid online transition to remote teaching.

\section{Supporting Faculty at a Four-year, Research- Intensive University}

Trending in the literature, academic continuity remains relevant compared to when it was first highlighted in research (Day, 2015; Regehr, et al., 2017). At the faculty level, specific plans for academic continuity was yet to be realized to the full extent possible. Administrators at various levels previously discussed continuity planning for the year, but it was never implemented at the faculty level. The time and energy needed to prepare a continuity plan always seemed like something that could be postponed. COVID-19 changed that pattern of thinking when what seemed like overnight, all instruction transitioned to remote delivery. The speed of the change caught faculty and administrators off guard. The faculty members generally fell into three groups, one group were
New articles in this journal are licensed under a Creative Commons Attribution 4.0 United States License. Program and is cosponsored by the University of Pittsburgh Press.

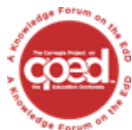

This journal is supported by the Carnegie Project on the Education Doctorate: A Knowledge Forum on the EdD (CPED) cpedinitiative.org 
experienced at online teaching or they used instructional technologies on a regular basis, another group consisted of faculty members who used instructional technologies in teaching on occasion, and the third group was comprised of those who seldom or never used instructional technology. North Carolina State University's (NC State's) centralized faculty development professionals met regularly to develop multifaceted approaches toward trying to meet the needs of faculty in all groups.

The first task was to develop an online website to help faculty with the transition to remote instruction. At this point, faculty members were being asked to have a plan completed in three weeks; however, the target kept moving and what started out as a plan for the future soon turned into a plan for the present time. The Keep Teaching website at NC State was designed and developed over a weekend through the tireless work of individuals from all over the campus. To reduce the time needed for deploying the site, the team searched for existing sites to replicate. Permission was obtained from Indiana University to replicate their site. One important addition to the resource developed for NC State is the inclusion of a template that faculty could use to submit their continuity plans to their department heads. This template can be downloaded in a variety of formats and helps faculty develop their continuity plans through answering a series of questions; however, a static, asynchronous website would not be enough to get through this emergency.

Synchronous webinars were delivered over Zoom to help faculty create their continuity plans. Similar to the Keep Teaching website, the Keep Teaching webinars were collaborative offerings between several centralized units that included an Office of Faculty Development, the instructional technology unit, Distance Education and Learning Technology Applications (DELTA), and the NC State Libraries in addition to many individuals from around campus. These hour-long webinars walked faculty through each part of the continuity plan template with the goal of leaving with a rough draft of a continuity plan. The webinars focused on answering questions about communicating with students, distributing course materials, delivering lectures, fostering communication between students, collecting assignments, and assessing student learning.

Additionally, webinars featuring experts from outside the university, were developed for the faculty. Two book authors, whose work was relevant to online instruction, were contracted to present hour-long webinars focused on responding to teaching and learning during the crisis. One webinar focused on universal design for learning and the other on student bandwidth issues. To address faculty and staff well-being during this crisis, a recurring program called Mindful Mondays was established and has received rave reviews from faculty and staff.

Ongoing and frequent communication was the key to getting through the initial crisis. To aid in communication efforts, the final part of the first phase of responding to the move to remote instruction was the creation of a blog designed to get information out to faculty in an informal and expedient way. The Faculty Focus blog focuses on helping faculty just in time. Blog posts have included topics related to implementing classroom assessment techniques, moving away from proctored exams, using grading rubrics, building community online, presenting to classes, and surviving the shift online. The posts are written by faculty development experts and faculty.

\section{DATA COLLECTION}

Nearly 900 instructors responded NC State's survey regarding their experiences regarding instructional continuity and the transition to online instruction during the Spring 2020 COVID-19 pandemic. The survey highlighted some issues, but also gave insight to how well the university did in meeting initial needs.

\section{FOUR-YEAR UNIVERSITY FACULTY DATA OVERVIEW}

One interesting finding was that $68 \%$ of instructors reported less than two years of experience with online instruction, with the majority of all respondents having no online teaching experience (Thornton, et al., 2020). The instructors continued to have major concerns for their students. For example, one participant stated:

My own internet is slow under neighborhood-overuse conditions, and many students have it even worse. One student drive into town each day, to work from his car in a parking lot. We do not have a public-utility-internet system that is strong enough to make internet-delivered classes universally accessible.

Even with high percentages of instructors with limited online teaching experience, $64 \%$ reported being somewhat or very comfortable with online instruction prior to the transition. Significant gains in preparedness were realized in deepening skills in instructional technologies and through adopting new student engagement strategies. Labs and course hand-offs continued to leave instructors feeling unprepared. Instructors were clear about what helped them make the transition, citing reliable universitysupported technologies such as Moodle and Zoom, peers and college IT personnel who were sought out for one-on-one help, and pan-university units such as the campus faculty development units and libraries (Thornton, 2020). It was difficult to know what information was getting onto faculty hands. As one faculty member participant said:

I know the university sent a ton of information to help, but it felt like too much, I was swimming through emails and videos just to find one small piece of information. I found it faster and easier to turn to a colleague who had online teaching experience.

In the future, messaging about resources needs to be better coordinated.

All units on campus were affected by the COVID-19 crisis and have responded in their own ways. For example, almost all colleges have implemented some sort of faculty support networks or programs where faculty support each other. The experience confirms that faculty development in times of crisis cannot be handled by a few centralized units. Now, more than ever, success relies on harnessing the expertise and knowledge from the entire university. 


\section{ROTL PROGRAM SUPPORTING FACULTY AT NORTH CAROLINA COMMUNITY COLLEGES}

Faculty scholars, who provide leadership and coordination to Ed.D. students in a CPED program, made the decision to commit to serving their community college colleagues by providing instructional design skills and years of online teaching and course design experience to help support the transition from face-to-face courses to online delivery. The partnership between the university and supporting the state's community colleges had already been established through the flagship doctoral program aimed at creating a pipeline for the next generation of community college executive leaders. With the mission to partner with the state's community colleges, utilizing decades of online instructional design expertise, the ROTL program was launched by two faculty scholars who designed and delivered a webinar designated to helping community college faculty with the quick transition to online teaching and learning.

The initial webinar was offered in March of 2020 on three separate dates with over 180 faculty members registering and attending. This level of interest led to the creation of the ROTL program that connected with 55 of the state's 58 community colleges, offering webinars, individual and group coaching, and the creation of short videos aimed at assisting faculty. Expert coaches were hired from around the country with expertise in various learning management systems (LMS) such as Moodle, Blackboard, Canvas, and Sakai. Coaches helped faculty members new to online learning understand fundamental online design and tools for engaging students. Coaches also assisted seasoned online instructors with the workload of transitioning content online.

Short videos were housed and shared from a newly created YouTube channel, with over 540 views of the videos in three months. Making way for the transfer of knowledge process, COVID-19 supported a revitalization of stakeholder relationships, representative of the community partnership model (Doorneweert, 2014; White et al., 2019). Even when not compounded by a quick timeline, transitioning to online teaching and learning requires a large amount of time and resources, such as access to technology and stable internet connection (Chen, 2007; Zhao, et al., 2005; Stone, 2017; Riedling, 2020). The ROTL program aimed to assist faculty members learn ways to connect their students to course content, peers, instructors, and the community in online learning environments. Beyond placing content online, instructors needed to support students, new to online learning, with the ability to successfully maneuver through online classes. While maintaining a focus on student engagement and utilizing limited resources was not a new concept for faculty (Warren \& Bartlett, 2019), it became evident that they were willing to expand their skill set to meet the needs of their students. Further, faculty members worked to remove barriers to student success by providing flexibility in assignment due dates or asynchronous options.

\section{DATA COLLECTION FOR ROTL TRANSITION PROGRAM}

Community college faculty perceptions were gathered from webinar evaluation forms, help requests, and coaching evaluations during the ROTL transition program. Faculty communicated other feedback through emails to team members and follow-up phone conversations. Data was not collected for research purposes but to best help community college faculty through the transition to online teaching and learning.

\section{FACULTY PERCEPTIONS OF THE ROTL TRANSITION PROGRAM}

Of the community college faculty members that worked with the program's coaches individually and/or participated in departmental training sessions, several gave feedback of how the program impacted them. Coaching goals were twofold: (a) help those that were new to online teaching and (b) be extra hands for seasoned online instructors who had not prepped for online teaching that particular semester. The assessment of the ROTL program was critical to the framework moving forward and participant feedback contributed to the evolving delivery of the services. Faculty members newer to online teaching were given the skills needed to transition which helped relay nerves of the upcoming shift as seen in the following faculty quotes, "I will be teaching virtually and <coach name> helped me every step of the way." and "I am sure that I will reach out again due to my trying to successfully adjust to the move from the classroom to the on-line environment without so much anxiety." More seasoned faculty members were helped by having extra hands to put content online, "...The only thing I could use help with at this point is man-power." Further, faculty members were help strategies to help beyond the ROTL, "I will incorporate the information and tips in my daily online instructional practices [to] improve the existing course.", "<Coach name $>$ give me some great ideas on how to engage with my students...", and "This information provided me with new insights and assistance regarding my current and future online coursework. I feel better prepared to teach online." Faculty also reported wanting to encourage peers to take part in the program as well, "I was humbled by the level and amount of assistance I received. I have already recommended this to my colleagues in my academic division. I hope they take advantage of it." and "<Coach name $>$ was great, I am thrilled this resource was made available to me! l've been sharing her insight with my other teacher friends. I feel confident and ready for this new challenge."

An existing challenge, exacerbated by COVID-19, is professional development for faculty and staff around digital literacy (Adam-Turner \& Burnett, 2018) and access to digital platforms in rural areas (Adam-Turner \& Burnett, 2018; Bailey, et al., 2015). Panic-gogy, coined by Kamenetz (2020), described feelings of faculty's initial reaction to transitioning classes online, mid-semester. Faculty showed remarkable grit, working extra hours and remaining determined to focus on their students' success. Faculty members remained intent on lifting their students through the tough time often while experiencing the same burdens themselves. As the semester progressed, they seemed to shift from 'panic' to 'vitality', defined by 
Dictionary.com (2020), is "exuberant...mental vigor...capacity for survival...". Vitality, combined with Andragogy, the guidelines of educating adults (Pratt, 1993), creates a term the researchers designate as "Vita-gogy" (Vitality + Andragogy).

\section{LESSONS LEARNED}

Faculty member concerns about transitioning to online teaching and learning under time pressure is covered in this section. Additionally, researchers share insights on findings around technology issues for faculty and students and continuity planning.

\section{Faculty Transition Concerns}

Faculty concerns that were addressed through webinars included, how to transition online, eAdvising, and ways to communicate with students online. Assistance was provided through individual coaching for a variety of topics, such as, setting up a Zoom, recording lectures, structuring the online course, and converting materials to a digital format. Larger problems such as managing an online presence, talking with mid-level leaders around communication and crucial conversations, and thinking through the process of delivering a truck driving training program online were tackled through group coaching. Short videos were created and shared for smaller technical solutions, such as embedding a video into an LMS, using web-conferencing tools, and managing active learning tools.

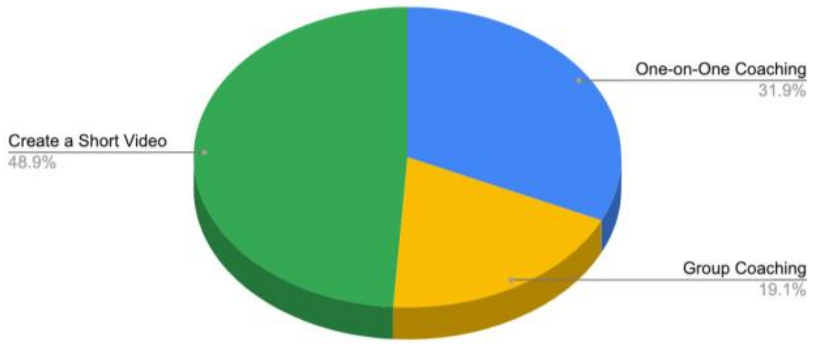

Figure 1. Types of Help Requested: Create a short video, one-onone coaching, and group coaching

As seen in Figure 1, the type of help most requested by the North Carolina community college faculty is the creation of a short video $(48.9 \%)$, then one-on-one coaching (31.9\%), and lastly group coaching (19.1\%). Problems that required brainstorming or solution finding centered around requests for FERPA training, communication regarding future semesters from administrators, and how to handle student cheating in online environments.

\section{Technology Issues for Students and Faculty}

Many students and a surprising number of faculty members at both the 4-year and 2-year colleges, reported having issues with access to high-speed internet at home, access to technology devices, and often found themselves sharing technology devices with other family members working from home and children learning remotely. Students struggled with finding quiet places to complete coursework while confined to their living space, often with other family members or roommates. A large number of students reported struggling with accessing course content and writing papers using their smartphones when they did not have access to technology devices. Both instructors and students mentioned issues with synchronous issues.

\section{ACADEMIC CONTINUITY MOVING FORWARD}

Now that postsecondary education has experienced the speed with which education can be disrupted, crisis situations must regularly be anticipated before they arise. The continuity plans developed by NC State faculty were in response to COVID-19. As such, the plans relied heavily on remote instruction assuming broadbased access to sophisticated technologies. However, this may not be the reality in the next disruption. Faculty members must plan now for how they will respond for different scenarios such as weather incidents where student and faculty access to the Internet and other technologies is limited (Regehr et al., 2017).

Community colleges, who serve as engines for social mobility for surrounding communities, serve both non-traditional and underserved students (Dougherty et al., 2017). In both community college and university settings, students often struggle with job, food, or housing insecurities that impede academic progress and create further challenges for completion (Dougherty et al., 2017; GoldrickRab, 2010; Seidman, 2005). Throughout the pandemic, community colleges provided continuity support to students in the form of resources, assignment revisions, increased help desk hours, and support for access to technology and devices and will continue in their role of serving the community. The virtual delivery of higher education courses shifted successfully because of the innovative ideas that emerged and the desire to keep students engaged.

\section{CONCLUSION}

Faculty at both the research-intensive land-grant university and the state community colleges were extremely student centered and remained focused on their students' success throughout the semester. Faculty often chose to push forward and lift their students, even while maneuvering themselves through stresses such as fear of pandemic exposure, partners working from home, financial and job insecurity, distance from loved ones, and children learning at home. Faculty reached out for assistance, joined with other faculty and coaches to create support communities, shared resources, and brainstormed solutions to quickly adapt their teaching practices.

\section{REFERENCES}

Adam-Turner, N., \& Burnett, D. D. (2018). Leadership perspectives of digital learning and digital literacy adoption at rural community colleges. The Community College Enterprise, 24(2), 21-48. https://www.schoolcraft.edu/cce/24.2.21-48.pdf

Bailey, T. R., Jaggars, S. S., \& Jenkins, D. (2015). Redesigning America's community colleges: A clearer path to student success. Harvard University Press.

Chen, S-J. (2007). Instructional design strategies for intensive online courses: An objectivist- constructivist blended approach. Journal of Interactive Online Learning, 6(1) http://pdf.aminer.org/000/270/261/online_learning_support_in_constructi vist_environments.pdf 
Day, T. (2015) Academic continuity: Staying true to teaching values and objectives in the face of course interruptions. Teaching and Learning Inquiry, 3(1), 75-89. DOI :https://doi.org/10.20343/teachlearninqu.3.1.75

Dictionary.com. (n.d.). Vitality. In Dictionary.com. Retrieved August $20^{\text {th }} 2020$, from https://www.dictionary.com/browse/vitality

Doorneweert, B. (2014, October 17). The partnership canvas. Partnership Design. https://valuechaingeneration.com/2014/10/17/the-partnershipcanvas/

Dougherty, K. J., Lahr, H., \& Morest, V. S. (2017). Reforming the American community college: Promising changes and their challenges (CCRC Working Paper No. 98). Community College Research Center, Teachers College, Columbia University website:

https://ccrc.tc.columbia.edu/media/k2/attachments/reforming-americancommunity-college-promising-changes-challenges.pdf

Goldrick-Rab, S. (2010). Challenges and opportunities for improving community college student success. Review of Educational Research, 80(3), 437-469. https://doi.org/10.3102/0034654310370163

Hodges, C., Moore, S., Lockee, B., Trust, T., \& Bond, A. (2020, March 27). The difference between emergency remote teaching and online learning. Educause Review. https://er.educause.edu/articles/2020/3/thedifference-between-emergency-remote-teaching-and-online-learning

Kamenetz, A. (2020, March 19). 'Panic-gogy': Teaching online classes during the coronavirus pandemic. NPR.

https://www.npr.org/2020/03/19/817885991/panic-gogy-teaching-onlineclasses-during-the-coronavirus-pandemic

Pratt, D. D. (1993). Andragogy after twenty-five years. New Directions for Adult and Continuing Education, 57(57), 15-23. https://doi.org/10.1002/ace.36719935704

Regehr, C., Nelson, S., \& Hildyard, A. (2017). Academic continuity planning in higher education. Journal of Business Continuity \& Emergency Planning,

11(1), 73-84.

Riedling, A. M. (2020). Distance education: The technology-what you need to know to succeed, an overview. AACE Review (formerly AACE Journal), 18(1), 8-13.

Seidman, A. (Ed.). (2005). College student retention: Formula for student success. Praeger.

Stone, C. (2017). Opportunity through online learning: Improving student access, participation and success in higher education. Perth: The National Centre for Student Equity in Higher Education (NCSEHE), Curtin University.

Thornton, C. (2020). Insights from survey of Spring 2020 instructors of record: Preparedness for the transition to online instruction (Full report). North Carolina State University. Executive summary available at https://provost.ncsu.edu/wp-content/uploads/2020/07/Spring-2020Instructor-Survey-Results-Executive-Summary.pdf

Thornton, C., Chapman, D. \& Stewart K. (2020, December). Insights from spring 2020: Preparedness for transitioning to online instruction. Lilly Online Conference (recorded presentation), November 30-December 5, 2020.

Warren, C., \& Bartlett, M. (2019, June 23). Creative strategies to support student engagement while expanding resources. [Conference Proceedings]. Distance Learning Administration 2019 Annual Conference, Jekyll Island, GA, United States.
White, G. R. T, Cicmil, S., Upadhyah, A., Subramanian, N., Kumar, V., \& Dwivedi, A. (2019). The soft side of knowledge transfer partnerships between universities and small to medium enterprises: An exploratory study to understand process improvement. Production Planning \& Control, 30(10-12), 907-918, doi:10.1080/09537287.2019.1582098

Zhao, Y., Lei, J., Yan, B., Lai, C., \& Tan, H. S. (2005). What makes the difference? A practical analysis of research on the effectiveness of distance education. Teachers College Record, 107(8), 1836. 